\section{How are Reading Disabilities Operationalized in Spain? A Study of Practicing School Psychologists}

\section{Abstract}

This study examines how 115 Spanish school psychologists rated the importance of certain criteria for identifying reading disabilities (RD), and compares their views with those of their US counterparts. The sample comprised school psychologists primarily between 30 and 39 years of age who had been in professional practice for less than ten years. The survey questions followed those used by Spanish practicing school psychologists ascribe the greatest importance to the discrepancy between listening and reading comprehension and to the IQ-achievement discrepancy criterion, while US school psychologists place greater emphasis on response to intervention (RTI) criteria and cognitive processing difficulties when operationalizing RD. Possible reasons for these differences are discussed. Differences between Spanish and US school psychologists are also observed in prioritizing which exclusion criteria were most important to consider when attempting to identify $\mathrm{RD}$, even though the most popular choices were mental retardation and inadequate instruction in both samples.

Keywords: Reading disabilities; Identification; School psychologists; Spain

Received: March 31, 2016; Accepted: June 23, 2016; Published: June 30, 2016

\section{Introduction}

In recent decades, the search for consensus regarding the conceptual definition of learning disabilities (LD) has focused primarily on what they are not rather than on what they actually are. In other words, the emphasis has been on establishing a set of exclusion criteria that could be applied when seeking to identify $\operatorname{LD}[1,2]$. This is reflected in the internationally recognized definition proposed by the National Joint Committee on Learning Disabilities [3] and backed by the ICD-10 [4] and the DSM-5 [5], a definition that is based predominantly on exclusion and discrepancy based criteria, without specifying how these should be quantified.

Research in this area has highlighted the wide range of models that may be used to identify and assess LD and, in particular, reading disabilities (RD), the most common kind of LD and the focus of this paper. The way RDs have been identified can be seen to evolve over recent decades, from diagnostic-criteria based models to models based on response to intervention. Diagnosticcriteria based models have been the most popular for assessing $\mathrm{RD}$, most notably those based on the discrepancy concept. The model that has proved most enduring internationally is based on

\section{González-Valenzuela MJ', Soriano-Ferrer $\mathbf{M}^{2}$, Delgado-Ríos $\mathbf{M}^{1}$ and Félix-Mateo $\mathbf{V}^{2}$}

\section{Developmental and Educational Psychology, University of Málaga, Spain \\ 2 Educational Psychology, University of Valencia, Spain}

\section{Corresponding author: \\ Myriam Delgado-Ríos}

\section{"delgadorios@uma.es}

Myriam Delgado-Ríos, University of Malaga, Developmental and Educational Psychology, Málaga, Spain.

Tel: +34952132484

Citation: González-Valenzuela MJ, SorianoFerrer M, Delgado-Ríos M, et al. How are Reading Disabilities Operationalized in Spain? A Study of Practicing School Psychologists. J Child Dev Disord. 2016, 2:3. the criterion of IQ-achievement discrepancy [6, 7]. This model affirms that subjects with RD are characterized by a discrepancy between IQ and achievement; in other words, they have normal IQ but their achievement is low. Some authors also have suggested that the discrepancy between listening comprehension and achievement would make a better criterion, basing their argument on the limited relevance of IQ to the diagnosis of RD [8-12]. However, in recent years, other diagnostic criteria for identifying RD have been proposed, quite distinct from those based on discrepancy. Similarly, suggest that low achievement scores could provide a sufficient basis for identifying RD, as the focus should be on the need for intervention, not on the assessment of IQ or the IQ-achievement discrepancy [13]. Other authors have focused their attention on the value of low scores in phonological awareness [14-17], or in cognitive processes [18-20] as criteria for diagnosing RD. A recent alternative to diagnostic-criteria based models is what is known as response to intervention (RTI), a model that likewise shifts the emphasis away from the ability-achievement discrepancy [21-33]. In this model, the child with RD is detected or identified by his or her immediate 
response to written instruction [24,34], where performance is severely low and there is an unexpected early learning difficulty shown by failure in their response to a standardized instruction $[26,29,35,36]$.

Despite these suggested alternatives to the IQ-achievement discrepancy as a criterion for defining RD, it is not clear whether there is consensus over which criteria might best replace the discrepancy requirement. In an attempt to address this issue [2], surveyed the opinions of experts regarding the key components of an operational definition of RD for use in practice; their reason for taking this approach was because expert opinion had not been considered and separate definitions may exist for research and practice. The survey was answered by editorial board members of four journals on learning disabilities and reading. The members who answered the survey were university professors with doctorates, graduates in Special Education, Psychology or Medicine, who are active researchers in RD. The most highly rated exclusion criteria were mental retardation, inadequate instruction and sensory deficits. Only $30 \%$ of those surveyed believed that the IQ-reading achievement discrepancy should be a marker. Three components were selected by over two-thirds of the respondents: reading achievement, phonemic awareness and treatment validity. It should also be noted that these results must be interpreted with caution, given that the survey does not consider or specify the importance of language characteristics in explaining RD, as is established in some studies. Namely, the predictive value of phonological processing has been shown to differ according to the consistency of the language in question, being greater in more consistent languages than in less consistent ones [37-42].

It is also important to note that in educational practice the operational definition of $\mathrm{RD}$ also varies from one country to another. In the USA, this definition has undergone a gradual and critical change over the last decade or so. Specifically, in 2002 the Commission on Excellence in Special Education (US Department of Education, Office of Special Education and Rehabilitation Services) proposed, with the agreement of the National Association of School Psychologists [43], that the IQ-achievement discrepancy model should be abandoned in favor of RTI. The Individuals with Disabilities Education Improvement Act [44] also recognized $\mathrm{RD}$ as a category of disability that was eligible for special education services, linking the concept more closely to a research base and the RTI model and moving away from an IQ-achievement discrepancy criterion. In Australia, this move away from IQ-achievement discrepancy models occurred earlier than in the USA [45, 46], while countries such as the United Kingdom [47], Japan [48] and Germany [49] either never adopted such an approach to the identification of RD or were quicker to shift towards a criterion focused on the need for remedial education [46].

Machek and Nelson [1] concluded that despite attempts for the better part of three decades, there has been little progress in narrowing the gap between the conceptual and operational definitions of RD. Thus, although there is some consensus among professionals over the need to align definitions, heated debate continues on the question of how reading disabilities should be measured in practice. These authors also stressed the importance of soliciting the opinions of school psychologists, who are responsible for identifying RD in the actual school setting. In particular, they argued that the attitudes, perceptions and beliefs of school-based professionals should be considered as part of any attempt to advance our understanding of how best to identify $\mathrm{RD}$, especially in relation to new proposals such as RTI. To this end, they examined practicing school psychologists' perceptions of the various operational components that should be included in any definition of RD, as well as the exclusion criteria they believed were most important when making an RD diagnosis. Their findings differed somewhat from those reported by Speece and Shekitka [2]. Specifically, the criteria regarded as most important by the school psychologists surveyed were RTI, phonological awareness, cognitive processing and the IQ-achievement discrepancy, while the exclusion criteria ascribed the greatest importance were inadequate instruction and mental retardation. These differences between the two studies could be the result of the changes proposed by the IDEIA (2004). In the context of research on the views of educational professionals regarding key criteria, a study of Australian school psychologists by [46] found that although $81 \%$ of them agreed that IQ tests were useful in the process of identifying RD, they used them not to assess the IQ-achievement discrepancy but because parents and teachers wanted this kind of information about a child's possible intellectual problems.

Given that the conceptual definition of RD has also undergone changes in our country, Spain, we wish to understand the impact that this has had on educational professionals. Briefly, the situation in Spain is as follows. The education act passed in 2006 [50], included and differentiated children with so-called specific learning disabilities as a distinct category within the wider pool of children regarded as needing special educational support (referred to in Spain by the initials NEAE). These legislative changes ushered in recognition of specific learning difficulties, such as RD, and of the educational needs of the children who presented them. However, the 2006 education act did not offer an operational definition of such difficulties, and left the responsibility for establishing diagnostic criteria to regional authorities. Consequently, and given that in Spain the school psychologists decide which children should receive special educational services in state schools, it seems important to examine the relative emphasis they place on different criteria when seeking to identify RD, and also to determine whether, in practice, their approach has changed as a result of advances in research. Depending on the findings that emerge, it may be helpful to propose guidelines for improving their work.

In light of the above, the present study had two objectives: First, to examine the importance ascribed by Spanish school psychologists to different criteria for identifying RD, and second, to compare their views with those of the school psychologists surveyed by Machek and Nelson [1]. In this way we hope to shed light on the effect of changes in the conceptual definition of RD on educational practice in Spain, and to examine the extent to which the effects observed are similar to those reported in the USA [1]. 


\section{Method}

\section{Participants}

The sample comprised 115 Spanish school psychologists (95 women and 20 men), who voluntarily responded to the survey. The total initial population of these professionals could not be known because there is no single register of all school psychologists in Spain. The criteria for selecting participants are described in the procedure. Information on certain sample characteristics (e.g., age, level of education) was collected under categories, as in the study [1], in order to establish meaningful comparisons.

The majority were women $\left(X^{2}=48.91, p<0.05\right)$, mostly between the ages of 30 and 39 years $\left(X^{2}=45.48, p<0.05\right)$ and having completed their studies during the period 2001-2012 $\left(X^{2}=16.37\right.$, $p<0.05)$. They were well distributed across different geographical regions of the country $\left(X^{2}=5.34, p>0.05\right)$. Significant differences were observed in terms of how long they had been practicing (the majority for fewer than 10 years and a minority for more than 30; $\left.M=15.54, S D=9.6 ; X^{2}=33.83, p<0.05\right)$, the type of school where they worked (the majority in the state system; $X^{2}=43.83$, $\mathrm{p}<0.05$ ), their academic qualifications (most did not have PhDs; $\left.X^{2}=74.73, p<0.05\right)$ and the number of special courses on RD they had completed (the majority had completed fewer than 5 courses; $\left.M=5.26, S D=7.14 ; X^{2}=34.51, \mathrm{p}<0.05\right)$. Table 1 presents a description of the sample.

In terms of the extent to which their academic training equipped them to identify RD, $50.4 \%$ reported feeling relatively well equipped, while $40 \%$ said they felt largely unprepared for this task. When asked how prepared they felt as a result of attending specific courses on RD, $44 \%$ said they were relatively well prepared and $32.2 \%$ felt largely unprepared.

Our sample of school psychologists was similar in many respects to that surveyed by Machek and Nelson [1], since the latter was also composed of more women (75.3\%) than men (24.7\%), most did not have a doctoral degree (73.4\%), and the sample was geographically well-distributed. However, the two samples differed in age, since the majority (52\%) of the US school psychologists were over age 50 . These data could not be compared statistically as specific information was not available for the sample in the reference study. A comparison of ethnicity across the two samples was not performed since all the Spanish school psychologists shared the same ethnic background. Nor could comparisons be made with regard to the number of years since qualification, the type of school in which the psychologists were employed, the number of years practicing or the number of specific courses on RD they had completed, since this information was not collected in the study [1].

\section{Instruments}

The instrument consisted of two parts. The first gathered demographic, professional, and academic information about the participants. This information referred to gender, age, degree, year of degree, type of school in which they were employed, geographical location, years of practice and training received on $\mathrm{RD}$.
Table 1 Description of the sample.

\begin{tabular}{|c|c|c|}
\hline & $\begin{array}{c}N \\
n=115\end{array}$ & $\%$ \\
\hline $\begin{array}{l}\text { Gender } \\
\text { Female } \\
\text { Male }\end{array}$ & $\begin{array}{l}95 \\
20\end{array}$ & $\begin{array}{l}82.6 \\
17.4\end{array}$ \\
\hline $\begin{array}{c}\text { Age (years) } \\
20-29 \\
30-39 \\
40-49 \\
50-59 \\
60-69\end{array}$ & $\begin{array}{c}6 \\
39 \\
27 \\
6 \\
6\end{array}$ & $\begin{array}{c}5.2 \\
33.9 \\
23.5 \\
32.2 \\
5.2\end{array}$ \\
\hline $\begin{array}{l}\text { Qualifications } \\
\text { Doctorate } \\
\text { No Doctorate }\end{array}$ & $\begin{array}{c}15 \\
100\end{array}$ & $\begin{array}{l}13.0 \\
87.0\end{array}$ \\
\hline $\begin{array}{c}\text { Year qualified } \\
1980 \text { or earlier } \\
1981-1990 \\
1991-2000 \\
2001-2012\end{array}$ & $\begin{array}{l}10 \\
34 \\
35 \\
36\end{array}$ & $\begin{array}{c}8.7 \\
29.6 \\
30.4 \\
31.3\end{array}$ \\
\hline $\begin{array}{l}\text { Type of school } \\
\text { State system } \\
\text { Publicly-funded private }\end{array}$ & $\begin{array}{l}93 \\
22\end{array}$ & $\begin{array}{l}80.9 \\
19.1\end{array}$ \\
\hline $\begin{array}{l}\text { Area of Spain } \\
\text { North } \\
\text { South } \\
\text { Central }\end{array}$ & $\begin{array}{l}32 \\
50 \\
33\end{array}$ & $\begin{array}{l}27.8 \\
43.5 \\
28.7\end{array}$ \\
\hline $\begin{array}{c}\text { Years practicing } \\
<10 \\
11-20 \\
21-30 \\
>30\end{array}$ & $\begin{array}{l}53 \\
29 \\
23 \\
10\end{array}$ & $\begin{array}{c}46.1 \\
25.2 \\
20.0 \\
8.7\end{array}$ \\
\hline $\begin{array}{c}\text { Courses completed } \\
\text { in RD } \\
<5 \\
>5\end{array}$ & $\begin{array}{l}89 \\
26\end{array}$ & $\begin{array}{l}77.4 \\
22.6\end{array}$ \\
\hline
\end{tabular}

The second took the form of an earlier survey conducted by Speece and Shekitka [2], and which was also used by Machek and Nelson [1]. The translation and adaptation of Speece and Shekitka's [2] original survey into Spanish was done in accordance with the guidelines described [51, 52]. This survey covered issues relating to the identification of RD and included 13 definitional items that sought to gather the views of school psychologists regarding different operational components of RD and the need to consider different exclusion criteria when defining RD.

Nine items assessed the degree of agreement/disagreement with different criteria for identifying RD, using a 5-point Likert-type scale (strongly disagree, disagree, agree, strongly agree, don't know). These criteria were IQ cut-off score (cut-off score established on the intelligence test), treatment validity/RTI (does not respond to well-planned, well-implemented general education Reading instruction, but does respond to individualized instruction), discrepancy between oral and written comprehension, difficulties in cognitive processing (e.g., memory, attention), phonological awareness cut-off score (cut-off score established on the test that assesses the ability to orally manipulate the sounds in words), reading achievement cut-off score (cut-off score established on the test of reading achievement), discrepancy between intelligence 
and reading achievement, discrepancies between achievement in different areas (reading vs. mathematics) and measurements based on the curriculum (not belonging to the measures taken in the response to treatment model). Two items asked which criteria were considered the first and the second most important for respondents. Finally, two items assessed if they considered that any exclusion criteria should be used together with the defining criteria for identifying RD, and if so, what these criteria were. The possible exclusion criteria from which to choose were mental retardation, emotional/behavioral disability, sensory deficits, economic disadvantage, cultural difference, inadequate instruction, and other criteria.

\section{Procedure}

Given that in Spain there is no single register of school psychologists, a number of different procedures were used to collect information. First, the heads of the school psychological services in some of the regional educational authorities provided contact information (telephone numbers and e-mail addresses) for their staff, after receiving a written request that explained the research aim. The survey and a cover letter explaining the purpose of the research was then sent to these school psychologists. The coordinators for each school and/or team were then contacted by telephone so as to inform them about the study and the fact that the school psychologists had been sent the survey by e-mail. They were asked to contact their corresponding school psychologist and encourage them to complete and return the survey. Thirteen professionals responded via this route.

In a separate procedure, for some of the regional educational authorities, the survey and a cover letter explaining the purpose of the research was sent in paper format by ordinary mail to the heads of the school psychological services, and they were asked to distribute the material to the coordinators of schools and/or staff teams for whom they were responsible. These coordinators handed out the material during a scheduled staff meeting, with the aim that the school psychologists would complete the survey. A total of 71 completed surveys were returned through this approach.

A third procedure involved the president of the Spanish Confederation of School Psychological and Counseling Services (in Spanish, COPOE), who sent all members an e-mail attaching the survey and the cover letter, and explaining the purpose of the research. Twenty professionals responded through this route.

Finally, the president of the COPOE also distributed copies of the survey among those attending the IV National Meeting of School Psychologists and Counselors. A further 11 professionals responded to this initiative.

\section{Data analysis}

In line with the approach taken [1], and in order to be able to compare the results from Spain with those from the USA, the survey responses were categorized into three levels (strongly agree/agree, strongly disagree/disagree, and don't know).

Percentages were calculated for each type of response for each of the criteria used to identify RD that was considered in the study [1], the aim being to determine similarities and differences between the two samples. A statistical analysis of differences could not be performed as raw data were not available for the US sample.

\section{Results}

\section{Definitional criteria}

\section{Answers from the spanish respondents}

When presented with the list of potential criteria for identifying specific RD, the proportion of Spanish school psychologists who strongly agreed or agreed with the need to use the criterion of IQ cut-off score was 54.8\%; the RTI criterion, 53.9\%; the criterion of discrepancy between listening and reading comprehension, 81.7\%; cognitive processing difficulties, 67\%; phonemic awareness cut-off score, 68.7\%; Reading achievement cut-off score, 62.6\%; IQ-achievement discrepancy, $74.8 \%$; intra-individual discrepancy, 60\%; and curriculum-based measurement, $53 \%$ (Table 2). Percentages of strongly agree/agree ranged between $81.7 \%$ and $53 \%$. The criterion which held the greatest agreement among Spanish respondents was the discrepancy between listening and reading comprehension (81.7\%), followed by the IQ-achievement discrepancy, the phonemic awareness cut-off score, cognitive processing difficulties, the reading achievement cut-off score and intra-individual discrepancy criteria (between $74.8 \%$ and $60.0 \%$ ). The lowest percentages of strong agreement/ agreement corresponded to the IQ cut-off score, the RTI criterion and curriculum-based measurement (between $54.8 \%$ and $53 \%$ ).

Table 2 also shows that the rate of strongly disagree/disagree responsesamongSpanishschoolpsychologistsfortheidentification criterion IQ cut-off score was $19.1 \%$; for the RTI criterion, $24.3 \%$; for the criterion Discrepancy between listening and reading comprehension, 6.1\%; for cognitive processing difficulties, $23.5 \%$,; for the phonemic awareness cut-off score, 3.5\%; Reading achievement cut-off score, 2.6\%; IQ-achievement discrepancy, 13\%; intra-individual discrepancy, 22.6\%; and curriculum-based measurement, $22.6 \%$. Percentages ranged between $24.3 \%$ and $2.6 \%$. The criteria for defining RD that produced the highest levels of strong disagreement/disagreement were treatment validity/ RTI, cognitive processing difficulties, intra-individual discrepancy, curriculum-based measurement and the IQ cut-off score (between $24.3 \%$ and $19.1 \%$ ), followed by the IQ-achievement discrepancy and the discrepancy between listening and reading comprehension (13\% and 6.1\%, respectively). The lowest levels of strong disagreement/disagreement corresponded to the criteria phonemic awareness cut-off score and the reading achievement cut-off score (3.5\% and $2.6 \%$, respectively).

The results also show that, for most of the criteria used to identify $\mathrm{RD}$, a high proportion of Spanish school psychologists answered 'don't know' when asked to rate their importance (Table 2). The highest rates of 'don't know' responses, ranging between $34.8 \%$ and $21.7 \%$, corresponded to the criteria reading achievement cutoff score (34.8\%), IQ cut-off score (26.1\%), phonemic awareness cut-off score $(26.1 \%)$, curriculum-based measurement $(24.3 \%)$ and treatment validity/RTI (21.7\%). These were followed by the discrepancy between achievement scores in different academic areas $(17.4 \%)$, the discrepancy between listening and reading 
comprehension (12.2\%), the IQ-achievement discrepancy (12\%), and, finally, cognitive processing difficulties (9.6\%) (Table 2). The majority of subjects who selected this response category, on some item, had anywhere from 13 to 17 years of experience, depending on the item $(M=16, S D=9.6)$, did not have a Ph.D. (between 70 and 92\%, depending on the item) and they had completed an average of 5.27 courses on RD (between 2 and 6 courses, depending on the item).

\section{Comparing the answers from the Spanish and American respondents}

The data presented in (Table 2 ) show results obtained in the study [1] and those obtained from Spanish respondents. For the criteria listening and reading comprehension, IQ cut-off score and IQ-achievement discrepancy, the Spanish psychologists showed $28.5 \%, 20.5 \%$ and $12.9 \%$ greater agreement, respectively, than did their US counterparts. However, the Americans showed $27.2 \%, 20.3 \%$ and $10.6 \%$ greater agreement, respectively, on the criteria treatment validity/RTI, curriculum-based measurement and cognitive processing difficulties. The smallest differences between the two samples corresponded to the criteria reading achievement cut-off score and phonemic awareness cut-off score (differences of $6.9 \%$ and $3.9 \%$, respectively) (Table 2).

In addition, the level of disagreement from Spanish psychologists for the criteria treatment validity/RTI, cognitive processing difficulties and curriculum-based measurement was $8.2 \%, 3.3 \%$ and $1.4 \%$ greater, respectively, than the corresponding figures for their US counterparts. However, the latter showed $42.1 \%$, 32.9\% and $27.9 \%$ greater disagreement, respectively, for the criteria IQ cut-off score, listening and reading comprehension discrepancy and reading achievement cut-off score (Table $\mathbf{2}$ ).

Moreover, these results show that Spanish school psychologists were much more likely to answer 'don't know' when asked to rate the importance of a criterion for identifying RD than were their US counterparts. Table 2 reveals that the percentage of Spanish psychologists responding 'don't know' was considerably higher for all the criteria considered, most notably for reading achievement cut-off score (a difference of $33.2 \%$ with respect to the US survey), followed by IQ cut-off score (24.1\%) and phonemic awareness cut-off score (23\%); then treatment validity/RTI and
CBN (19.1 and 19.9\%, respectively); and finally, IQ-achievement discrepancy (9.6\%), cognitive processing difficulties (8\%) and discrepancy between listening and reading comprehension (5.5\%) (Table 2).

Finally, in relation to the diagnostic criteria, responses from the Spanish school psychologists were rather evenly distributed among the response options. When the Spanish respondents selected more than one diagnostic criteria, first place was given to IQ-achievement discrepancy (17.4\% of respondents), discrepancy between listening and reading comprehension (13.9\%) and cognitive processing difficulties (11.3\%). For the second most important criterion, the Spaniards selected reading achievement cut-off score (13\%), phonemic awareness cut-off score (12.2\%) and discrepancy between listening and reading comprehension (11.3\%). This contrasts with the views of the US school psychologists surveyed by Machek and Nelson [1], where the top three choices for the most important criterion were treatment validity (32.8\%), phonemic awareness cut-off score (16.9\%) and cognitive processing disabilities (13.8\%).

\section{Exclusion criteria}

When asked about the use of different exclusion criteria when identifying RD, $67.8 \%$ of Spanish school psychologists said that exclusion criteria should be included in the definition of RD, whereas $30.4 \%$ felt that no such criteria should be used. Most of this group held no doctorate (approximately 85\%), they had an average of 15 years of practice and had completed an average of about 5 training courses in RD.

Certain differences are observed in how the two samples prioritize exclusion criteria, although both samples concur in giving high priority to mental retardation and inadequate instruction. Table 3 shows that the three exclusion criteria regarded as most important by the Spanish psychologists were mental retardation, sensory deficits and inadequate instruction, with less importance ascribed to emotional/behavioral disability, cultural differences and economic disadvantage.

The exclusion criteria regarded as most important by US school psychologists were inadequate instruction and mental retardation, with less weight given to cultural differences, sensory deficits, emotional/behavioral disability and economic disadvantage (Table 3).

Table 2 Percentage of strongly agree/agree and strongly disagree/disagree responses for each of the RD criteria, showing a comparison between the present survey and the Machek and Nelson survey [1].

\begin{tabular}{|c|c|c|c|c|c|c|}
\hline Criterion & $\begin{array}{c}\text { Strongly agree/ } \\
\text { agree }\end{array}$ & $\begin{array}{c}\text { Machek and } \\
\text { Nelson }\end{array}$ & Strongly disagree/disagree & $\begin{array}{c}\text { Machek and } \\
\text { Nelson }\end{array}$ & Don't Know & $\begin{array}{l}\text { Machek and } \\
\text { Nelson }\end{array}$ \\
\hline IQ cut-off score & $54.8(63)$ & $34.3(188)$ & $19.1(22)$ & $61.2(336)$ & $26.1(30)$ & $2.0(11)$ \\
\hline Treatment validity/RTI & $53.9(62)$ & $81.1(445)$ & $24.3(28)$ & $16.1(88)$ & $21.7(25)$ & $2.6(14)$ \\
\hline $\begin{array}{l}\text { Discrepancy between listening and } \\
\text { reading comprehension }\end{array}$ & $81.7(94)$ & $53.2(292)$ & $6.1(7)$ & $39.0(214)$ & $12.2(14)$ & $6.7(37)$ \\
\hline Cognitive processing difficulties & $67.0(77)$ & $77.6(426)$ & $23.5(27)$ & $20.2(111)$ & $9.6(11)$ & $1.6(9)$ \\
\hline Phonemic awareness cut-off score & $68.7(79)$ & $75.6(415)$ & $3.5(4)$ & $20.6(113)$ & $26.1(30)$ & $3.1(17)$ \\
\hline Reading achievement cut-off score & $62.6(72)$ & $66.5(365)$ & $2.6(3)$ & $30.5(167)$ & $34.8(40)$ & $1.6(9)$ \\
\hline IQ-achievement discrepancy & $74.8(86)$ & $61.9(340)$ & $13.0(15)$ & $35.0(192)$ & $12.0(14)$ & $2.4(13)$ \\
\hline Intra-individual discrepancy & $60.0(69)$ & & $22.6(26)$ & & $17.4(20)$ & \\
\hline Curriculum-based measurement & $53.0(61)$ & $73.3(402)$ & $22.6(26)$ & $21.2(116)$ & $24.3(28)$ & $4.4(24)$ \\
\hline
\end{tabular}


Table 3 Most important exclusion criteria chosen by the psychologists surveyed.

\begin{tabular}{|c|c|c|}
\hline Criterion & $\begin{array}{c}\text { Current } \\
\text { sample (\%) }\end{array}$ & $\begin{array}{c}\text { Machek and } \\
\text { Nelson (\%) }\end{array}$ \\
\hline Mental Retardation & 60 & 66.5 \\
\hline Sensory Deficits & 47.8 & 29.3 \\
\hline Inadequate Instruction & 43.5 & 67.6 \\
\hline Emotional/Behavioral Disability & 33.9 & 26.2 \\
\hline Cultural Differences & 32.2 & 34.4 \\
\hline Economic Disadvantage & 28.7 & 25.5 \\
\hline
\end{tabular}

In both the Spanish and US surveys, mental retardation was the most widely endorsed exclusion criterion, although the percentage was slightly higher (by $6.5 \%$ ) in the study [1]. The least frequently endorsed exclusion criterion in both surveys was economic disadvantage, although in this case the percentage was slightly higher (by $3.2 \%$ ) in our study. The remaining exclusion criteria were endorsed by varying proportions of Spanish and US school psychologists. The greatest difference in the rate of endorsement corresponded to inadequate instruction as an exclusion criterion (24.1\% higher among US psychologists), followed by the differences for sensory deficits, emotional/ behavioral disability and cultural differences (differences between the Spanish and US samples between $18.5 \%$ and $2.2 \%$ ).

\section{Discussion}

The aim of this study was to examine the importance that Spanish school psychologists ascribe to certain criteria for identifying $\mathrm{RD}$ and to compare their views with those of the US school psychologists surveyed by Machek and Nelson [1].

Results show that the criteria most commonly endorsed by Spanish school psychologists were the discrepancy between listening and reading comprehension and the IQ-achievement discrepancy. The greatest differences between the two samples in the agreement percentage for criteria for identifying RD corresponded to the discrepancy between listening and reading comprehension, IQ cut-off score and IQ-achievement discrepancy (endorsed by a higher percentage of Spanish school psychologists) and treatment validity/RTI (endorsed by a higher percentage of US psychologists). Regarding disagreement with proposed criteria, the Spanish respondents yielded higher percentages for treatment validity/RTI and cognitive processing difficulties as criteria for identifying RD. In this response category, the greatest differences between the two samples were observed for the IQ cut-off score, listening and reading comprehension discrepancy and reading achievement cut-off score (all endorsed more frequently by US psychologists), as well as for the criteria treatment validity/RTI, cognitive processing difficulties and curriculum-based measurement (all endorsed more frequently in the Spanish sample). The analysis also shows that the percentage of Spanish psychologists responding 'don't know' was considerably higher than the corresponding figure in the US survey for all the criteria considered, most notably for the reading achievement cut-off score; the lowest rate of don't know' answers among Spanish psychologists corresponded to the criterion cognitive processing difficulties. Another difference between the two surveys was observed in relation to the criterion regarded as most important for identifying RD: the criterion most widely endorsed by Spanish school psychologists was the IQachievement discrepancy, as opposed to treatment validity/RTI in the sample of US psychologists. As regards exclusion criteria that should be applied when identifying RD, both the Spanish and US samples emphasized mental retardation and inadequate instruction, in line with the findings of Speece and Shekitka [2]. Economic disadvantage was the least frequently endorsed exclusion criterion in both the Spanish and US surveys.

Our results highlight the range of criteria that may be used by school psychologists to identify difficulties in learning to read, and show that the importance ascribed to the various criteria differs across countries. A number of reasons may be responsible for these differences, such as recent changes in the conceptual definition and how it is approached or applied in professional practice, the influence of language characteristics in explaining these problems, and the respondent's professional experience or level of education, to name a few.

In the USA, until recently, children with specific learning difficulties (SLD) were identified on the basis of the IQ-achievement discrepancy, which involved comparing their intellectual ability with their academic performance. However, the value of this approach to defining and identifying children with LD was questioned by various researchers [13, 22-24, 26-31, 33]. This was given legislative support in 2004 through the Individuals with Disabilities Education Improvement Act [44], which established the use of a response to intervention (RTI) approach in professional practice as an alternative to the IQ-achievement discrepancy [35]. In the USA this has led to a considerable shift in the way in which LD are conceptualized and identified, and has brought the conceptual and operational definitions much closer together. The RTI model has become increasingly popular in the years since, and now features prominently in many training programs for school psychologists [53-55]. As already noted in the introduction to this paper, this shift in emphasis occurred much earlier in countries such as Australia, the United Kingdom, Japan and Germany, where the IQ-achievement criterion was either never adopted or was more swiftly abandoned as the basis for identifying LD [46-49], being replaced with a criterion that considered the need for remedial education.

It is also worth noting that in Spain neither general nor specific LD were recognized as problems that required special educational attention prior to the education act that was passed in 1990 [56]. Under this act, LD began to be considered as a broad category of difficulties within the wider framework of special educational needs (SEN). Children were classified as having SEN if their academic achievement was below what would be expected for their age and if they failed to respond to a standard teaching approach. In 2005, one of Spain's autonomous regions, the Canary Islands, proposed a new diagnostic category within the framework of SEN. The aim of this category, known in Spanish as desajuste de aprendizaje (or delayed learning), was to distinguish children who present some kind of learning discrepancy, whether as high achievers or from having sensory, motor, or intellectual deficits, general developmental disorders, or multiple deficits [30]. Some regional governments subsequently passed their own 
regional education acts. In Andalusia, for example, the act passed in 2007 [57] provided the first official recognition in this region that children with LD had special educational needs. The current situation in Andalusia is that children with LD are distinguished not only from those with SEN (i.e., those with general developmental disorders; sensory, motor, and intellectual deficits; behavioral disorders and ADHD; and speech disorders), but also from those with high intellectual ability and from socially disadvantaged children, with all of them being considered under the umbrella term of 'NEAE', that is, children who need special educational support [58]. Thus, in Andalusia, children with LD are those who need special educational support due to impairment in the basic cognitive processes required by learning, where this impairment interferes in both their academic achievement (they must be at least one year behind if enrolled in primary education or two years behind at secondary level) and their daily activities; however, the impairment must not be the result of a diagnosed sensory, motor or intellectual deficit, or be due to a severe emotional disorder or to educational or socio-cultural factors. At present, under the term 'learning disabilities', a distinction is made between specific learning difficulties (such as RD), difficulties due to delayed language development and difficulties that result from borderline intellectual ability, although the criteria that must be considered when seeking to identify these problems are not formally set out.

On the other hand, even today the discrepancy model is suggested for government services in Spain for identification of RD. Thus, the RTI model was not used until a few years ago and its use is not generalized to all regions; this model has recently been introduced experimentally in one region of Spain, namely the Canary Islands $[29,59,60]$. These reasons might explain some of the difference from the American school psychologists in considering diagnostic models (e.g. discrepancy between listening and reading comprehension, IQ cut-off score and IQachievement discrepancy) and the RTI model.

The influence of language characteristics is also considered relevant for explaining results and differences between the two samples. The two samples show a striking difference in their consideration of the criteria discrepancy between listening and reading comprehension and phonemic awareness cut-off score. Specifically, the Spanish respondents agree more with the first criterion than do their U.S. counterparts, and they are less in agreement with the second criterion than are the Americans. This may be a reflection in practice of what research results have shown, that the value of oral language and of phonological processing is different in more consistent languages, such as Spanish, from their value in less consistent languages such as English [37-42]. In more consistent languages, phonological processing is more important than orthographic processing, while in less consistent languages, orthographic processing is more important [38]

On the other hand, another reason for these findings may be respondents' professional experience or level of education. Most of the psychologists surveyed did not have a doctoral degree, they had fewer than 10 years of experience (in the case of the Spaniards), they had not completed many specific training courses in RD, and they did not feel well prepared after completing the training courses they had taken. Such factors may explain why the Spanish sample ascribed more importance to diagnostic models than to the RTI model, and even why there were high percentages of the "don't know" response on most items, or even why some of the respondents saw no need for exclusion criteria. It would be useful for future studies to establish how such variables influence the opinion of practicing psychologists on identifying RD, in the line of other research studies such $[1,2,46]$.

Finally, regarding exclusion criteria for identification of RD, there is agreement between the Spanish and American psychologists in selecting mental retardation and inadequate instruction as high priorities. The distinction between these problems and RD has been a priority study objective in this field for decades, and furthermore, both international classification systems, the ICD-10 and DSM-5, concurrently refer to the unexpectedness of poor performance as a crucial component of the concept of reading disabilities. This concept of unexpected underachievement implies that reading disorders attributable to intellectual disabilities, sensory problems, or insufficient instruction, among other conditions, should not be identified as Reading disabilities [61].

\section{Limitations}

First, the size of the Spanish sample was limited due to low participation from the psychologists contacted. With a larger sample, there might have been less variability in the responses and results would be more suitable for generalization.

Second, some of the items included in the measurement instrument might be considered ambiguous as they are currently expressed (e.g. IQ cut-off score, Reading achievement cut-off score, etc.). It is reasonable to think that this may have affected the high percentages of "don't know" responses on most items.

On the other hand, even though the criteria considered here are the ones that are most represented in recent research and educational practice, there is a need to include proposals that have appeared since the studies [1, 2]. Along these lines, certain investigations indicate that the RTI model is effective for improving reading achievement as long as certain conditions are met, but it is ineffective for identifying specific learning disabilities [35] propose the Components Model of Reading (CMR) as an alternative to the discrepancy or RTI models. This model takes into account three domains: cognitive components (word recognition and comprehension), psychological components (motivation, locus of control, teacher expectations, gender differences and learned helplessness) and ecological components (behavior at home, culture and parental involvement, classroom environment, peer influences, dialects, ELL). This model evaluates reading performance from a multidimensional perspective that facilitates more adequate instruction for the reader, with better chances for success.

Finally, since we did not have access to the raw data from [1], we were unable to perform inferential statistical analyses in order to compare the results from the two study samples. This implies that the results and subsequent conclusions of this descriptive study should be taken with caution. 


\section{Conclusion}

This study has newly illustrated the existing controversy about the criteria to be used in identifying RD. While in some countries the operational definition of LD (including RD) is closer to the conceptual definition from the latest research, this is less so in the case of countries such as Spain.

This may be largely due to the fact that the legislation of each country does not equally reflect the progressive evolution of identification criteria in the research. . In this regard, changes in the conceptual definition of LD, and of RD specifically, should lead to changes in both educational law and professional practice, but as Reschly notes: "If disability category designation is not required by state or federal law, it is highly likely that most of the demand for the administration of individual ability measures will be substantially reduced. There are places where such reforms have been instituted..." [62]. This is one reason why it is important to draw up educational legislation that ensures that the specific criteria used by each country to identify RD are based on the latest research findings.

Further aspects that merit attention include the influence of language characteristics in explaining these problems, and the professional experience and level of education of the practicing psychologists. Language differences could explain why all identification criteria would not have the same value in every language, and therefore, as in the conceptual definition of RD, these specific questions must be considered. Also important is that research advances become known among the professionals, allowing them to increase their knowledge and put into practice the new research findings. This suggests that there is a need to design and implement continuing education programs that can help professionals keep up to date with both changes in the conceptualization of RD and the most suitable criteria for identifying them. Indeed, it would appear that specific protocols are needed to ensure more effective detection and diagnosis of RD, and also that teachers and school psychologists are adequately trained in how to apply them. It is in this regard that clear and common criteria must be set out, based on the latest research on $\mathrm{RD}$.

In sum, the lack of consensus regarding the identification of RD, previously identified in other countries and now observed in this survey of Spanish school psychologists, is largely determined by the conceptual changes in identification of RD and the legislative recognition that each country gives to such disabilities. Thus, although some progress has been made, a gap remains between the conceptual and operational definitions of RD. This highlights the need to develop international legislation or agreements that would help harmonize these definitions, such that professional practice can be brought into line with the findings of applied research.

Future studies should analyze and compare the opinions of researchers and professional psychologists in different countries with different languages, for the purpose of consolidating the definition and identification of $\mathrm{RD}$, taking into consideration opinions from the spheres of research and of professional practice. 


\section{References}

1 Machek GR, Nelson JM (2007) How should reading disabilities be operationalized? A survey of practicing school psychologists. Learn Disabil Res Pract 22: 147-157.

2 Speece DL, Shekitka L (2002) How should reading disabilities be operationalized? A survey of experts. Learn Disabil Res Pract 17: 118-123.

3 National Joint Committee on Learning Disabilities (1994) Collective perspectives on issues affecting learning disabilities. Austin, TX:PROED-ED.

4 WHO (2001) World Health Organization.

5 Asociación Americana de Psiquiatría (2014) Diagnostic and Statistical Manual of Mental Disorders ( $5^{\text {th }}$ edn.) Arlington, VA: American Psychiatric Publishing.

6 Bateman B (1965) An educator's view of a diagnostic approach to learning disorders. In: Hellmuth J (ed.), Learning disorders. Seatle: Special Child Publications.

7 Kavale KA (2002) Discrepance models in identification of learning disability. In: Bradley R, Danielson L, Hallahan DP (eds.) Identification of learning disabilities: Research to practice. Mahwah, NJ: Erlbaum, pp: $369-426$.

8 Aaron PG (1995) Differential diagnosis of reading disabilities. School Psych Rev 24: 345-360.

9 Stanovich KE (1989) The sociopsychometrics of Learning Disabilities. J Learn Disabil 22: 350-361.

10 Stanovich KE (1991) Discrepancy definitions of Reading disability: Has intelligence led us astray? Read Res Q 26: 1-29.

11 Stanovich KE, Stanovich PJ (1996) Rethinking the concept of learning disabilities: the demise of aptitude/achievement discrepance. In: Olson DR, Torrance N (eds.) The handbook of educational and human development. Oxford: Blackwell, pp: 117-147.

12 Kauffman AS, Kauffman NL (2001) Specific learning disabilities and difficulties in children and adolescents. Psychological assessment and evaluation. Cambridge: Cambridge University Press, pp: 218-243.

13 Siegel LS, Ladyman S (2000) A review of special education in British Columbia. Victoria, BC: British Columbia Ministry of Education.

14 Adams MJ (1990) Beginning to read: Thinking and learning about print. Cambridge, M.A.: MIT Press.

15 Rodrigo M, Jiménez JE (2000) IQ vs phonological recoding skill in explaining differences between poor readers and normal readers in Word recognition: Evidence from a naming task. Reading and Writing: An international Journal 12: 129-142.

16 Stanovich KE (1988) Explaining the differences between the dyslexic and the garden variety poor reader: The phonological-core variabledifference model. J Learn Disabil 21: 590-612.

17 Torgesen JK (2002) The prevention of reading disabilities. J Sch Psychol 40: 7-26.

18 Kavale KA, Forness SR (2000) What definitions of learning disability say and don't say: A critical analysis. J Learn Disabil 33: 239-256.

19 Naglieri JA, Das JP (1997) Cognitive assessment system. Itasca, II: Riverside.

20 Siegel LS (1989) IQ is irrelevant to the definition of learning disabilities. J Learn Disabil 25: 618-629.
21 Case LP, Speece DL, Molloy DE (2004) The validity of a response-tointervention paradigm to identify reading disabilities: A longitudinal analysis of individual differences and contextual factors. School Psych Rev 32: 557-582.

22 Denton CA, Fletcher JM, Anthony JL, Francis D (2006) An evaluation of intensive interventions for student with persistent reading difficulties. J Learn Disabil 39: 447-466.

23 Fletcher JM, Coulter WA, Reschly DJ, Vaughn S (2004) Alternative approaches to the definition and identification of learning disabilities: some questions and answers. Ann Dyslexia 54: 304-331.

24 Fletcher JM, Vaughn S (2009) Response to intervention: preventing and remediating academic difficulties. |Child Dev Perspect 3: 30-37.

25 Fuchs LS, Fuchs D (1998) Treatment validity: A unifying concept for reconceptualizing the identification of learning disabilities. Learn Disabil Res Pract 13: 204-219.

26 Fuchs D, Fuchs LS (2006) Introduction to response to intervention. What, why, and how valid is it? Read Res Q 41: 93-99.

27 Fuchs D, Fuchs LS, Compton DL (2004) Identifying reading disabilities by responsiveness to intervention: Specifying measures and criteria. Learn Disabil Q 25: 33-45.

28 Grigorenko EL (2009) Early grade reading assessment toolkit. World Bank and RTI International. Washington, DC.

29 Jiménez JE (2010) Response to Intervention (Rtl) Model: A promising alternative for identifying students with learning disabilities? Psicothema 22: 932-934.

30 Jiménez JE (2012) Dislexia en español. Madrid: Piramide.

31 Lembke S, McMaster K, Stecher P (2009) The prevention science of research within a response-to-intervention model. |Psychol Schools 47: 22-35.

32 Siegel LS (1999) Issues in the definitions and diagnosis of learning disabilities. J Learn Disabil 32: 304-319.

33 Vellutino FR, Scalon, DM, Zhang H, Schatscheneider C (2008) Using response to kindergarten and first grade intervention to identify children at-risk for long-term reading difficulties. Reading and Writing: An interdisciplinary Journal 21: 437-480.

34 Vaughn S, Wanzek J, Woodruff AL, Linan-Thompson S (2007) Prevention and early identification of students with reading disabilities. In: Haager D, Klinger J, Vaughn S (eds.) Evidence-based reading practices for response to intervention. Baltimore MD: Paul H. Brookes Publishing, pp: 11-28.

35 Carreker S, Joshi M (2010) Response to intervention: Are the Emperor's clothes really new? Psicothema 22: 943-948.

36 Fuchs D, Dreshler D (2007) What we need to know about responsiveness to intervention (and shouldn't be afraid to ask). Learn Disabil Res Pract 22: 129-136.

37 Babayigit S, Stainthorp R (2011) Modeling the relationships between cognitive-linguistic skills and literacy skills: New insights from a transparent orthography. J Educ Psychol 103: 169-189.

38 Georgiou GK, Parrilla R, Papadopoulos TC (2008) Predictors of word decoding and reading fluency across languages varying in orthographic consistency. J Educ Psychol 100: 466-580.

39 Landerl K, Wimmer H (2008) Development of word reading fluency and spelling in a consistent orthography: An 8-year follow-up. J Educ Psychol 100: 150-161. 
40 Lei L, Pan J, Liu H, McBride-Chang C, Li H, et al. (2011) Developmenta trajectories of reading development and impairment from ages 3 to 8 years in Chinese children. J Child Psychol Psychiatry 52: 212-220.

41 Nag S, Snowling MJ (2012) Reading in an alphasyllabary: Implications for a language universal theory of learning to read. Sci Stud Read 16: 404-423.

42 Xue J, Shu H, Li H, Li, W, Tian X (2013) The stability of literacy-related cognitive contributions to Chinese character naming and reading fluency. J Psycholinguist Res 42: 433-450.

43 National Association of School Psychologists (2002) Learning disabilities criteria: Recommendations for change in IDEA reauthorization. NASP Communiqué 39.

44 Individuals with Disabilities Education Improvement Act of 2004 (IDEIA) Public Law No: 108-446, § 614.

45 Elkins J (2001) Learning disabilities in Australia. In Hallahan DP, Keough BK (eds.) Research and global perspectives in learning disabilities: Essays in Honour of Wiilims M. Cruickshank. Mahwah NJ: Lawrence Erlbaum, pp: 181-96.

46 Klasen RM, Neufeld P, Munro F (2005) When IQ is irrelevant to the definitions of learning disabilities. Sch Psychol Int 26: 297-316.

47 Reason R (2001) Eductional Practice and dyslexia. The Psychologist 14: 298-301.

48 Tsuge M (2001) Learning Disabilities in Japan. In Hallahan DP, Keough BK (eds.) Research and global perspectives in learning disabilities: Essays in Honour of Wiilims M. Cruickshank. Mahwah NJ: Lawrence Erlbaum, pp: 181-96.

49 Opp G (2001) Learning Disabilities in Germany: A retrospective analysis, current status and future trends. In Hallahan DP, Keough BK (eds.) Research and global perspectives in learning disabilities: Essays in Honour of Wiilims M. Cruickshank. Mahwah NJ: Lawrence Erlbaum, pp: 181-96.

50 Organic Law 2/2006 of 3 May, of Education. Official Gazette, No. 116, May 4, 2006.

51 Muñiz J, Elosúa, P, Hambleton RK (2013) Guidelines for the translation and adaptation of test: second edition. Psicothema 25: 151-157.
52 Muñiz J, Hambleton RK (1996) Guidelines for the translation and adaptation of test. Papeles del Psicólogo 66: 63-70.

53 Deno SL (2002) Problem solving as best practice. In: Thomas A, Grimes J (eds.) Best practices in school psychology IV. Bethesda MD: National Association of School Psychologists, pp: 37-55.

54 Reschly DJ, Ysseldyke JE (2002) Paradigm shift: The past is not the future. In: Thomas A, Grimes J (eds.) Best practices in school psychology IV. Bethesda, MD: National Association of School Psychologists, pp: 3-20.

55 Tilly WD (2002) Best practices in school psychology as a problemsolving enterprise. In Thomas A, Grimes J (eds.) Best practices in school psychology IV. Bethesda MD: National Association of School Psychologists, pp: 21-36.

56 Organic Law 1/1990 of 3 October on the General Educational System. Official Gazette, No. 238, October 4, 1990.

57 Organic Law 17/2007 of 10 December on the Education of Andalusia. Official Gazette of the Government of Andalusia, No. 256, December 26, 2007.

58 Fernández C (2012) Circular of September 10, 2012 of the General address equity participation and establishing criteria and guidelines for the registration and updating of data in the census of students with special educational needs in the information system " Seneca " are established. Sevilla: Consejería de Educación Junta de Andalucía, pp: 1-12.

59 Jiménez JE, Baker DL, Rodríguez C, Crespo P, Artiles C, et al. (2011) Evaluation of learning progress in reading within a Model Response to Intervention ( RIT) in the Canary Islands. Escr Psicol 4: 56-64.

60 Jiménez JE, Rodríguez C, Crespo P, González D, Artiles C, et al. (2010) Implementation of Response to Intervention (Rtl) Model in Spain: An example of a collaboration between Canarian universities and the department of education of the Canary Islands. Psicothema 22: 935-942.

61 Fletcher JM, Francis DJ, Morris RD, Lyon GR (2005) Evidence-based assessment of learning disabilities in children and adolescents. J Clin Child Adolesc Psychol 34: 506-522.

62 Reschly DJ (1997) Utility of individual ability measures and public policy choices for the 21st century. School Psych Rev 26: 234-243. 